EDITORIAL

\title{
Sex differences and cardiovascular risk
}

\author{
A Cordero, E Alegria
}

\section{Cardiovascular risk factors such as diabetes confer differing degrees of risk in men and women}

S ince cardiovascular risk factors (CVRF) were first identified, risk stratification has been based on the presence of such conditions. The social and cultural changes that occidental countries have experienced in the last decades have contributed to the increase of cardiovascular complications, despite the advances in knowledge and prevention of the atherogenic process. ${ }^{1}$

The burden of cardiovascular diseases and the increasing awareness of new risk factors related to insulin resistance (metabolic syndrome, ${ }^{2}$ nonhigh density lipoprotein (HDL) cholesterol, ${ }^{3}$ or hypertriglyceridaemia ${ }^{4}$ ) or systemic vascular inflammation (C reactive protein ${ }^{5}$ ) have amplified the interest in cardiovascular prevention. In addition, screening of subclinical atherosclerosis, especially coronary heart disease, has arisen as a highly relevant issue for the primary stratification of patients with intermediate risk. ${ }^{7}$ Anklebrachial index, coronary calcification evaluated by electron beam tomography, or intima-media thickness are some of the non-invasive tools for the evaluation of systemic atherosclerosis. The evaluation of intima-media thickness is currently recommended to improve risk assessment in intermediate risk patients, ${ }^{7}$ and a recent report of the atherosclerosis risk in communities (ARIC) study ${ }^{8}$ demonstrates its relation with the presence of metabolic syndrome, and the excess of coronary heart disease.

\section{WOMEN AND CARDIOVASCULAR DISEASE}

Most series, in the present and past decades, show concordant data on the fact that women suffer cardiovascular complications at older age, and more frequently fatal myocardial infarction, than men. ${ }^{9}$ The very recent INTERHEART study, $^{10}$ an impressive case-control study of myocardial infarction, had an especial interest in sex differences. Female cases of myocardial infarction were eight years older than male cases; also, hypertension and diabetes were found to confer higher risk in women. Moreover, the protective strategies evaluated, exercise and moderate alcohol consumption, appeared to be more protective in women compared to men. The Strong Heart Study ${ }^{11}$ demonstrated that diabetes increases the prevalence of CVRF much more in women, suggesting that insulin resistance reduces sex differences in a CVRF and tends to cluster such CVRF in a different manner between both sexes; a result also described in the INTERHEART
Heart 2006;92:145-146. doi: 10.1136/hrt.2005.069187

study. Both studies described sex differences in cardiovascular risk by the assessment of classical risk factors, such as hypertension or diabetes, but also novel parameters such as waist circumference, apolipoprotein $\mathrm{B}$, or the size of low density lipoprotein (LDL) particles.

Metabolic syndrome, ${ }^{212}$ homocysteine, ${ }^{13}$ nonHDL cholesterol, ${ }^{3}$ and C reactive protein ${ }^{14}{ }^{15}$ have been identified in the last decades as CVRF that confer higher risk in women. The predictive value of $C$ reactive protein for a first myocardial infarction, even more than LDL cholesterol values, was clearly demonstrated in the Women's Health Study. ${ }^{6}$ Subsequent cohort studies have shown that women's $\mathrm{C}$ reactive protein concentrations are higher compared to men, and this difference is larger when the metabolic syndrome is present. ${ }^{1214} 15$ In a prospective analysis of the ARIC study ${ }^{13}$ homocysteine was found to confer a twofold risk of incident coronary complications only in women. Classically, menopause and oestrogenic status have been proposed as the reason for sex differences in cardiovascular risk and complications, but the identification of these novel risk factors might amplify and variegate the approach of cardiovascular protection and risk stratification, tacking into account such sex differences.

\section{DIABETES}

Myocardial infarction and cardiovascular disease continue to be the primary cause of mortality in western societies. Prevention and treatment of acute and chronic heart diseases have dramatically improved in the last decades; unfortunately, women, and especially those with diabetes, have not followed the same tendency. The elegant comparison of two US cohorts ${ }^{16}$ (two National Health and Nutrition Examination Surveys, 197193) has revealed that although cardiovascular related mortality decreased slightly in men with or without diabetes, it increased in women with diabetes over the last three decades. This observation was attributable to the improvement in the control of CVRF and treatments of acute events, while the risk attributable to diabetes remained unchanged and subjects with diabetes would have benefited less from improved medical strategies.

The article by Erdogan and colleagues ${ }^{17}$ in this issue of Heart adds valuable information in this field, demonstrating that the effect of a nonclassical risk factor considered an accurate surrogate marker of insulin resistance, ${ }^{18}$ hypertriglyceridaemia, correlates with intima-media thickness only in women. Hypertriglyceridaemia is usually

Abbreviations: ARIC, atherosclerosis risk in communities; CVRF, cardiovascular risk factors; HDL, high density lipoprotein; LDL, low density lipoprotein 
associated with low HDL cholesterol concentrations and obesity, and both are probably linked by an insulin resistance state. ${ }^{2418}$ Insulin resistance and inflammation are underlying factors in patients with obesity or diabetes mellitus, exposing them to a higher cardiovascular risk and opening different pathways to atherothrombosis and complications. ${ }^{19}$ The clarification of novel mechanism of atherosclerosis connected to the identification of non-classical CVRF may help to select preventive and therapeutic targets more precisely.

\section{Authors' affiliations}

A Cordero, E Alegria, Department of Cardiology. Clínica Universitaria de Navarra, Pamplona, Spain

\section{REFERENCES}

1 Braunwald E. Shattuck lecture - cardiovascular medicine at the turn of the millennium: triumphs, concerns, and apportunities. N Engl J Med 1997;337:1360-69

2 Reaven GM. Role of insulin resistance in human disease. Diabetes 1988:37:1595-607.

3 Cui Y, Blumenthal RS, Flaws JA, et al. Non-high density lipoprotein cholesterol level as a predictor of cardiovascular disease mortality. Arch Intern Med 2001;161:1413-19.

4 Criqui $M$, Heiss $G$, Cohn R, et al. Plasma triglycerides level and mortality from coronary heart disease. Circulation 1993;328:1220-25.

5 Ross R. Atherosclerosis - an inflammatory disease. N Engl J Med 1999;340:115-26

6 Ridker PM, Rifai N, Rose L, et al. Comparison of C-reactive protein and lowdensity lipoprotein cholesterol levels in the prediction of first cardiovascular events. N Engl J Med 2002:347:1557-65.

7 Greenland P, Smith SC, Grundy SM. Improving coronary heart disease risk assessment in asymptomatic people. Role of traditional risk factors and non invasive cardiovascular test. Circulation 2001;104:1863-67.
8 McNeil AM, Rosamond WD, Girman CJ, et al. Prevalence of coronary heart disease and carotid arterial thickening in patients with the metabolic syndrome (the ARIC Study). Am J Cardiol 204, 94:1249-54.

9 Sans S, Puigdefábregas A, Paluzie G, et al. Increasing trends of acute myocardial infarction in Spain: the MONICA-Catalonia study. Eur Heart J 2005;26:505-15

10 Yusuf S, Hawken S, Ounpuu S, et al. Effect of potentially modificable risk factors associated with myocardial infarction in 52 countries (the INTERHEART study): case-control study. Lancet 2004;364:937-52

11 Howard BV, Cowan LD, Go O, et al. Adverse effects of diabetes on multiple risk cardiovascular risk factors in women. The strong heart study. Diabetes Care 1998:21:1258-65.

12 Alexander CM, Landsman PB, Teutsch SM, et al. NECP-defined metabolic syndrome, diabetes, and prevalence of coronary heart disease among NHANES III participants age 50 years and older. Diabetes 2003;52:1210-14

13 Folsom AR, Nieto J, McGovern PG, et al. Prospective study of coronary heart disease incidence in relation to fasting total homocysteine, related genetic polymorphisms, and $B$ vitamins. The atherosclerosis risk in communities (ARIC) study. Circulation 1998:98:204-10.

14 Sattar N, Gaw A, Scherbakova O, et al. Metabolic syndrome with and without C-reactive protein as a predictor of coronary heart disease and diabetes in the West of Scotland coronary prevention study. Circulation 2003;108:414-9.

15 Rutter MK, Meigs JB, Sulliva LM, et al. C-Reactive protein, the metabolic syndrome, and prediction of cardiovascular events in the Framingham offspring study. Circulation 2004;110:380-85.

16 Gu K, Cowie CC, Harris MI. Diabetes and decline in heart disease mortality in US Adults. JAMA 1998;281:1291-97.

17 Erdogan D, Gullu H, Caliskan $M$, et al. Fasting hypertriglyceridaemia increases carotid intima-media thickness and impairs coronary microvascular functions in non-obese middle aged women but not in men. Heart 2005;91:259-60.

18 McLaughlin T, Abbasi F, Cheal K, et al. Use of metabolic markers to identify overweght individuals who are insulin resistant. Ann Intern Med 2003;139:802-9.

19 Moreno PR, Fuster V. New aspects in the pathogenesis of diabetic atherothrombosis. J Am Coll Cardiol 2004;44:2293-300.

\section{STAMPS IN CARDIOLOGY}

\section{Millennium stamps}

${ }^{\mathrm{O}}$ mark the new millennium a large number of countries issued stamps to celebrate achievements over the preceding years. A few of these had a medical theme and a very small proportion were relevant to cardiology/cardiac surgery. The first human heart transplant and Christiann Barnard were commemorated with the 6400 Lei Stamp from Romania (panel A). Christiann Barnard was also featured on the Millennium miniature sheet from Bhutan celebrating "Breakthroughs in modern medicine - 100 years" (panel B). Other medical personalities on the same sheet were Albert Calmette (tuberculosis vaccine), Camillo Golgi and Ramon y Cajal (discovery of the neurone), Alexander Fleming (penicillin), Jonas Salk (polio vaccine) and Luc Montagnier (Aids research). The Commonwealth of Dominica also released a set of 10 stamps including one commemorating Christiann Barnard (panel C). Others in the set were again Fleming, Golgi, and Salk as well as Louis Pasteur, Sir Frank MacFarlane Burnet (immunology), Har Gobind Khorana (genetics), and Elizabeth Black (first woman physician).

M K Davies A Hollman
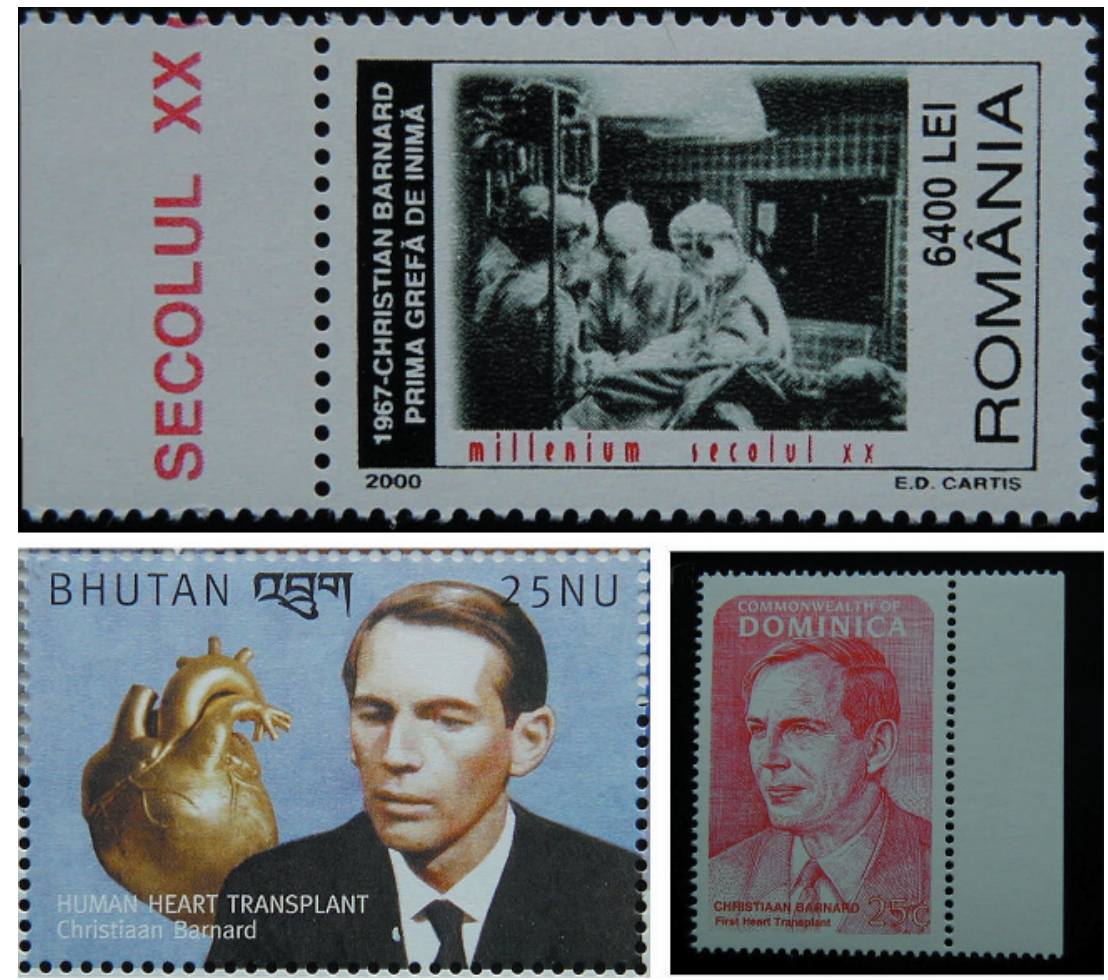